\title{
Principles of prophylactic and therapeutic management of skin toxicity during treatment with checkpoint inhibitors
}

\author{
Grażyna Kamińska-Winciorek¹, Bozena Cybulska-Stopa², Iwona Lugowska ${ }^{3,4,5}$, Marek Ziobro², Piotr Rutkowski³ $^{3}$ \\ ${ }^{1}$ Department of Bone Marrow Transplantation and Onco-Hematology, Maria Skłodowska-Curie Institute - Oncology Center, Gliwice \\ Branch, Gliwice, Poland \\ ${ }^{2}$ Maria Skłodowska-Curie Institute - Oncology Center, Krakow Branch, Krakow, Poland \\ ${ }^{3}$ Department of Soft Tissue/Bone Sarcoma and Melanoma, Maria Skłodowska-Curie Institute - Oncology Center, Warsaw, Poland \\ ${ }^{4}$ Department of Epidemiology and Biostatistics, Mother and Child Institute, Warsaw, Poland \\ ${ }^{5}$ Early Phase Clinical Trials Unit, Warsaw, Maria Skłodowska-Curie Institute - Oncology Center, Warsaw, Poland
}

Adv Dermatol Allergol 2019; XXXVI (4): 382-391

DOI: https://doi.org/10.5114/ada.2018.80272

\begin{abstract}
The introduction of immunotherapy into the treatment of cancer patients has revolutionised the oncological approach and significantly improved patient survival. The key drugs are immune checkpoint inhibitors (CPIs), whose mechanism of action is to elicit immune response against cancer cell antigens. Three types of CPIs are currently used and approved: an anti-CTLA-4 antibody, ipilimumab; anti-PD-1 antibodies, nivolumab and pembrolizumab; and anti-PD-L1 antibodies: atezolizumab, avelumab and durvalumab. CPIs have been widely used in metastatic and adjuvant melanoma settings, metastatic lung cancer, Hodgkin's lymphoma, renal cancer, bladder cancer, head and neck tumours, and Merkel cell carcinoma. However, side effects of CPIs differ from toxicities of other oncological drugs. According to literature data, in 10-30\% of patients CPIs are responsible for immune-related adverse events (irAE) associated with excessive activation of the immune system. Systemic irAEs include enterocolitis, pneumonitis, hepatitis, nephritis, hypophysitis, and autoimmune thyroid disease. However, the most common irAEs of checkpoint inhibitors are dermatologic toxicities ranging from pruritus and mild dermatoses to severe reactions including Stevens-Johnson syndrome and toxic epidermal necrolysis. Each irAE can become serious if not early diagnosed and appropriately treated. In the article we present different types of skin irAEs related to CPIs together with the recommended therapies.
\end{abstract}

Key words: skin toxicities, immune checkpoint antibody.

\section{Introduction}

The use of immunotherapy in the treatment of cancer patients has revolutionised modern oncology and significantly improved the outcomes of cancer treatment. However, a distinction should be made between immunotherapy with monoclonal antibodies to surface receptors of cancer cells, and treatment with antibodies against immune checkpoints (immune checkpoint inhibitors - ICls). The former, classical passive immunotherapy antibodies, work by blocking receptors for intracellular conduction pathways, which inhibits proliferation, induces apoptosis of target cells and, consequently, significantly impairs the proliferation of cancer cells. This group of antibodies includes, among others, trastuzumab, pertuzumab, pa- nitumumab and cetuximab [1]. On the other hand, the activity of checkpoint inhibitors consists in inducing their own immune response against various neoplastic antigens by blocking receptors responsible for lymphocyte inactivation. The purpose of the patient's own immune response is to destroy cancer cells with specific antigens and to induce long-term immune response of the body (through lymphocytes) by providing immunological memory (the so-called inhibition of immunotolerance) [2, 3]. Immune checkpoints include CTLA-4, PD-1 and PD-L1. Cytotoxic T-lymphocyte antigen 4 (CTLA-4), located on $T$ cells, is the primary regulator of the activity of these lymphocytes. An antibody binding to CTLA-4 immune checkpoint blocks the inhibitory signalling for $T$ cells, induced by the CTLA-4 pathway, leading to an increase

Address for correspondence: Assoc. Prof. COI Grażyna Kamińska-Winciorek MD, PhD, Department of Bone Marrow Transplantation and Onco-Hematology, Maria Skłodowska-Curie Institute - Oncology Center, Gliwice Branch, 15 Wybrzeże Armii Krajowej Ave, 44-101 Gliwice, Poland, phone: +48 604070 208, e-mail: dermatolog.pl@gmail.com Received: 11.09.2018, accepted: 27.09.2018. 
in the number of activated effector $T$ cells that mobilise T cells for a direct immune attack against tumour cells. Another immunoreceptor is the programmed cell death 1 (PD-1) receptor, which undergoes induced expression on $T$ cells as well as B cells. It is a negative regulator of immune response. Through interactions with its ligands, PD-L1 and PD-L2, expressed in many types of tissues, PD-1 is responsible for maintaining peripheral tolerance by limiting the activation, proliferation and effector functions of T cells. The expression of PD-1 and its ligands has been reported in many types of tumours, where they are important in modelling the microenvironment, and may also be associated with the escape of tumour cells from immune surveillance. Antibodies to PD-1/PD-L1, by inhibiting the binding of PD-1 with PD-L1 and PD-L2, support the activity of $T$ cells, including the anticancer response $[4,5]$.

The introduction of checkpoint inhibitors in the form of anti-CTLA-4, anti-PD-1 and anti-PD-L1 antibodies significantly prolonged the survival of patients with metastatic forms of melanoma and lung cancer. These agents have also been used in the adjuvant treatment of melanoma patients and in the treatment of Hodgkin's lymphoma, advanced kidney cancer, bladder cancer, Merkel cell cancer, head and neck cancer, and other solid tumours [6-16]. Six ICls have been approved by the US Food and Drug Administration (FDA) in the United States and by the European Medicines Agency (EMA) in Europe for use in various cancers: a CTLA-4 inhibitor, ipilimumab; PD-1 inhibitors, nivolumab and pembrolizumab; PD-L1 inhibitors, atezolizumab, avelumab and durvalumab.

Unfortunately, the use of ICls is also associated with the risk of new, previously unknown, adverse events, socalled immune-related adverse events (irAEs), which are often severe and unpredictable.

Immune complications associated with excessive activation of the immune system may affect virtually any system and organ and may occur at different stages of treatment (often even after the end of immunotherapy), which adds to this problem. Mild initial symptoms may suddenly become significantly worse and severe; therefore, it is extremely important to diagnose irAEs correctly, to determine their severity, and use the appropriate treatment as soon as possible after the onset of an irAE. The most common irAEs include skin complications, which may already occur at the beginning of treatment.

This article presents various types of irAEs affecting the skin, and the recommendations for prophylactic and therapeutic management in case they occur.

\section{Frequency and time of onset of skin lesions during therapy with checkpoint inhibitors}

The most common immune-related adverse events (irAEs) associated with the use of ICls include the following skin symptoms: maculopapular rash, dermati- tis, itching and vitiligo-like depigmentation of the skin. Immune-related complications affecting the skin have been reported in 45-65\% of ipilimumab-treated patients and $30-40 \%$ of patients treated with anti-PD- 1 inhibitors [17-20]. In most cases, they are mild (grade 1/2) according to Common Terminology Criteria for Adverse Events (CTCAE) [21]. Severe symptoms of dermal toxicity are rare ( $<3 \%$ cases with anti-PD-1 monotherapy and $<5 \%$ in combined therapy with anti-CTLA-4 and anti-PD-1) and usually do not require discontinuation of immunotherapy. Skin symptoms, other than vitiligo, appear relatively early after the beginning of therapy, usually during the first weeks of treatment (3-6 weeks).

They usually resolve in a few weeks and (with the exception of vitiligo) are reversible. In most cases, their severity depends on the dose of the immunological drug. Vitiligo is usually associated with a better response to anti-PD-1 therapy in patients with melanoma [17-20, 22].

In the case of combination therapy with ipilimum$\mathrm{ab}$ and an anti-PD-1 inhibitor, skin complications were reported in $62 \%$ of cases, most frequently in the form of pruritus, rash, dermatitis, urticaria, vitiligo, bullous pemphigoid and lichenoid dermatitis. Grade 3/4 dermal toxicities were reported in $1 \%$ of cases during nivolumab therapy and in $1.5 \%$ during pembrolizumab therapy. These complications usually occurred earlier during therapy with nivolumab ( $4^{\text {th }}-8^{\text {th }}$ week of therapy) compared to pembrolizumab (23 $3^{\text {rd }}$ week of therapy). Serious (grade $3 / 4$ ) skin irAEs are rare.

It is very difficult to accurately describe the prevalence and clinical nature of skin irAEs (the lesions are usually treated collectively as rash) due to the relatively short duration of use of ICls and the lack of precise dermatological terms in most published studies.

\section{Description of the most common skin lesions during $\mathrm{ICI}$ therapy}

In terms of histology, skin lesions associated with the use of ICls can be classified into four groups: inflammatory lesions as a manifestation of acute, subacute or chronic dermatitis, immune-related bullous diseases, keratinocyte disorders, immune-related melanocytic disorders. The classification is presented in Table 1 [18].

\section{Maculopapular rash}

During ipilimumab therapy, it usually occurs in the $3^{\text {rd }}-4^{\text {th }}$ week after the beginning of treatment [9] and mainly affects the skin of the body and extremities (Figure 1) [23]. It has the form of small, vivid red papulae merging into larger plaque lesions, often accompanied by desquamation [17, 19]. During treatment with anti-PD-1 agents, it may also occur at the beginning of therapy; however, in patients treated with nivolumab, maculopapular rash occurs after 3 weeks to 2 years, and in those treated with pembrolizumab, between 
Table 1. Types of dermatologic toxicities reported with anti-CTLA-4, anti-PD-1 and PDL-1 antibody therapy [18]

\begin{tabular}{|c|c|c|c|c|c|c|}
\hline Category & Dermatologic toxicity & Clinical presentation & Histologic feature & Anti-CTLA-4 & Anti-PD-1 & Anti-PDL-1 \\
\hline \multirow[t]{19}{*}{ Inflammatory } & Acneiform & Not reported & Not reported & Yes & Yes & Yes \\
\hline & $\begin{array}{l}\text { AGEP (acute generalized } \\
\text { exanthematous } \\
\text { pustulosis) }\end{array}$ & $\begin{array}{l}\text { Oedematous, } \\
\text { erythematous pustules }\end{array}$ & $\begin{array}{l}\text { Subcorneal } \\
\text { neutrophils with } \\
\text { eosinophils }\end{array}$ & Yes & Yes & Yes \\
\hline & $\begin{array}{l}\text { CD30 lymphomatoid } \\
\text { reaction }\end{array}$ & $\begin{array}{l}3 \text { to } 6-\mathrm{mm} \text { pink papules } \\
\text { coalescing into plaques on } \\
\text { the abdomen and back }\end{array}$ & $\begin{array}{l}\text { CD30+ lymphoid } \\
\text { infiltrate with } \\
\text { overlying } \\
\text { epidermal } \\
\text { hyperplasia }\end{array}$ & Yes & No & No \\
\hline & Dermatomyositis & $\begin{array}{l}\text { Photo-distributed, } \\
\text { erythematous eruption on } \\
\text { the face and upper chest, } \\
\text { erythematous papules } \\
\text { over the dorsal hand, nail } \\
\text { fold and eyelid erythema, } \\
\text { muscle weakness }\end{array}$ & Not performed & Yes & No & No \\
\hline & $\begin{array}{c}\text { DHR (dermal } \\
\text { hypersensitivity reaction) }\end{array}$ & $\begin{array}{l}\text { Maculopapular eruption on } \\
\text { the trunk and extremities }\end{array}$ & $\begin{array}{c}\text { Perivascular } \\
\text { lymphocytic } \\
\text { inflammation with } \\
\pm \text { eosinophils and } \\
\text { spongiosis }\end{array}$ & Yes & Yes & Yes \\
\hline & $\begin{array}{l}\text { DRESS (drug reaction } \\
\text { with eosinophilia and } \\
\text { systemic symptoms) }\end{array}$ & $\begin{array}{l}\text { Diffuse maculopapular } \\
\text { rash with erythroderma }\end{array}$ & Not performed & Yes & No & No \\
\hline & Eczema/spongiotic & & & No & Yes & Yes \\
\hline & Erythema/erythematous & & & No & Yes & Yes \\
\hline & Exfoliative & & & No & Yes & Yes \\
\hline & Lichenoid/interface & Not reported & Not reported & Yes & Yes & Yes \\
\hline & Maculopapular & & & No & Yes & Yes \\
\hline & $\begin{array}{l}\text { Pityriasis lichenoides } \\
(\mathrm{PL}) \text {-like skin lesions }\end{array}$ & & & No & Yes & Yes \\
\hline & Photosensitivity & $\begin{array}{c}\text { Erythematous macules } \\
\text { on sun-exposed sites } \\
\text { with subsequent plaques } \\
\text { on the scalp, trunk and } \\
\text { extremities }\end{array}$ & $\begin{array}{l}\text { Spongiotic } \\
\text { dermatitis with } \\
\text { eosinophils and } \\
\text { parakeratosis and } \\
\text { acanthosis }\end{array}$ & Yes & Yes & Yes \\
\hline & Psoriasiform & & & No & Yes & Yes \\
\hline & Pyoderma gangrenosum & $\begin{array}{l}\text { Ulcerated, erythematous } \\
\text { nodule }\end{array}$ & $\begin{array}{l}\text { Ulcer with } \\
\text { neutrophilic } \\
\text { dermal } \\
\text { inflammation }\end{array}$ & Yes & No & No \\
\hline & $\begin{array}{c}\text { Radiation-associated } \\
\text { dermatitis }\end{array}$ & $\begin{array}{l}\text { Blisters within the radiated } \\
\text { area }\end{array}$ & Not performed & Yes & Yes & Yes \\
\hline & Sweet syndrome & $\begin{array}{c}\text { Erythematous, tender } \\
\text { papules and plaques } \\
\text { on the face, trunk and } \\
\text { extremities }\end{array}$ & $\begin{array}{l}\text { Papillary dermal } \\
\text { oedema and } \\
\text { neutrophilic } \\
\text { inflammation }\end{array}$ & Yes & No & No \\
\hline & $\begin{array}{l}\text { SJS/TEN (Stevens-John- } \\
\text { son syndrome/ toxic epi- } \\
\text { dermal necrolysis) }\end{array}$ & Not specified & $\begin{array}{l}\text { Skin necrosis and } \\
\text { vasculitis }\end{array}$ & Yes & Yes & Yes \\
\hline & Vasculopathic & & & No & Yes & Yes \\
\hline
\end{tabular}


Table 1. Cont.

\begin{tabular}{|c|c|c|c|c|c|c|}
\hline Category & Dermatologic toxicity & Clinical presentation & Histologic feature & Anti-CTLA-4 & Anti-PD-1 & Anti-PDL-1 \\
\hline \multirow[t]{2}{*}{ Immunobullous } & Bullous pemphigoid & & & No & Yes & Yes \\
\hline & Dermatitis herpetiformis & $\begin{array}{c}\text { Pink papules, grouped } \\
\text { near the elbows, back and } \\
\text { buttocks }\end{array}$ & $\begin{array}{l}\text { Collection of } \\
\text { neutrophils in the } \\
\text { papillary dermis, } \\
\text { IgA deposits in the } \\
\text { dermal papillae }\end{array}$ & Yes & No & No \\
\hline \multirow{6}{*}{$\begin{array}{l}\text { Alteration of } \\
\text { keratinocytes }\end{array}$} & Actinic keratosis & & & No & Yes & Yes \\
\hline & Basal cell carcinoma & & & No & Yes & Yes \\
\hline & Grover's disease & $\begin{array}{c}\text { Papulokeratotic eruption } \\
\text { on the trunk }\end{array}$ & $\begin{array}{l}\text { Acantholytic } \\
\text { dyskeratosis }\end{array}$ & Yes & Yes & Yes \\
\hline & Prurigo nodularis & Not reported & Not performed & Yes & No & No \\
\hline & Seborrheic keratosis & & & No & Yes & Yes \\
\hline & Squamous cell carcinoma & & & No & Yes & Yes \\
\hline \multirow[t]{3}{*}{$\begin{array}{l}\text { Alteration of } \\
\text { melanocytes }\end{array}$} & $\begin{array}{l}\text { Regression of } \\
\text { melanocytic naevi }\end{array}$ & $\begin{array}{l}\text { Unremarkable clinically, } \\
\text { DELM, alteration in } \\
\text { pigment with areas of } \\
\text { hyperpigmentation }\end{array}$ & $\begin{array}{c}\text { Lichenoid } \\
\text { lymphocytic } \\
\text { inflammation of } \\
\text { CD8+ lymphocytes } \\
\text { associated with } \\
\text { naevus cells }\end{array}$ & Yes & Yes & Yes \\
\hline & Tumoral melanosis & $\begin{array}{l}\text { Multiple purple, black } \\
\text { papules and nodules } \\
\text { coalescing into plaques }\end{array}$ & $\begin{array}{c}\text { Nodular } \\
\text { aggregates } \\
\text { of pigmented } \\
\text { macrophages in } \\
\text { dermis, absence of } \\
\text { viable melanoma } \\
\text { cells }\end{array}$ & Yes & No & No \\
\hline & Vitiligo & Hypopigmentation & $\begin{array}{l}\text { Dead melanocytes } \\
\text { along dermal- } \\
\text { epidermal } \\
\text { junction with } \\
\text { associated dermal } \\
\text { lymphocytic } \\
\text { inflammation }\end{array}$ & Yes & Yes & Yes \\
\hline
\end{tabular}

6 and 20 weeks of therapy [17]. Skin lesions usually have the form of numerous, scattered maculopapular lesions (sometimes accompanied by desquamation), with or without itching. They are located mainly in the upper part of the body and on the skin of the limbs, with a predominance of the upper limbs. Histopathological examination reveals perivascular eosinophilic infiltrates and lymphocytic infiltrates, often coexisting with peripheral eosinophilia [17].

The occurrence of maculopapular rash during antiPD-1 inhibitor therapy is the most common adverse event and usually correlates with histopathological image typical of lichenoid dermatitis or interface dermatitis [17]. In some patients, papular lesions tend to spontaneously resolve approximately 8 weeks after the beginning of treatment, whereas lichenoid lesions may occur as

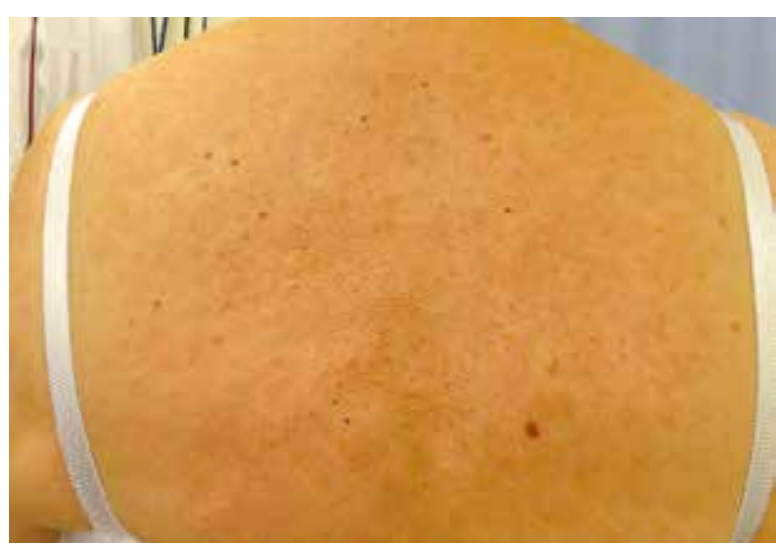

Figure 1. Maculopapular rash (CTCEA grade 2) in a patient treated with anti-PD-1, located in the neckline, back and shoulders, with onset in the $8^{\text {th }}$ week of treatment 
late as a few months after the beginning of therapy with anti-PD-1 and anti-CTLA-4 inhibitors.

\section{Vitiligo-like depigmentation}

Vitiligo-like depigmentation is relatively common, and has been reported in more than $25 \%$ of patients with stage III or IV advanced melanoma receiving nivolumab or pembrolizumab [24]. It has been hypothesised that PD-1 inhibitors induce vitiligo-like depigmentation in melanoma patients via the immune response by targeting healthy melanocytes owing to overlapping antigen expression. This side effect is observed after a few weeks of CPI therapy and in the majority of cases it does not resolve after interruption or discontinuation of treatment. Recently published data show that vitiligo-like depigmentation has been associated with a favourable response to treatment, especially in patients with metastatic melanoma receiving pembrolizumab [24] or nivolumab [25]. The limitations of these studies include relatively small cohorts of enrolled patients; therefore, these findings require validation in larger studies. The evaluation of other cancer immunotherapies (vaccines, antibody-based or adoptive transfer treatments) has shown a strong association between vitiligo-like depigmentation and survival (data from a meta-analysis of 137 studies) [26]. Clinically, vitiligo-like depigmentation may be located within metastatic melanoma lesions in the skin (Figure $2 \mathrm{~A}$ ), often in the area of a scar after excised melanoma with local recurrence (Figure $2 \mathrm{~B}$ ), sometimes not only within metastatic lesions throughout the body (Figure 2 C), but also with a tendency to form white halo surrounding benign melanocytic naevi (Figure 2 D). Moreover, they can resemble classic forms of vitiligo with discolouration in typical locations - over the dorsal hands, or segmentally on the trunk (Figure $2 \mathrm{E}$ ).

\section{Pseudoprogression}

The assessment of response to CPI treatment is challenging and should be performed by experienced oncologists. A substantial proportion of patients treated with ICls do not respond to treatment, while a small proportion of patients have a survival benefit regardless of the initially observed treatment failure (pseudoprogression). Some melanoma patients treated with ipilimumab, who experienced an initial increase in tumour size with subsequent decrease of tumour burden, have biopsy-confirmed inflammatory cell infiltrates or necrosis in metastatic lesions [27]. Pseudoprogression and immune-related patterns of mixed response pose a growing clinical challenge. In contrast to classical chemotherapy, patients may continue immunotherapy even in the presence of tumour enlargement or new tumour lesions on imaging scans based on irRECIST criteria. The decision problem is to discontinue treatment in select patients who have true disease progression. Continua- tion of CPI therapy postpones the alternative treatment options and increases the risk of immune-related adverse events.

\section{Inflammation}

The immune activation and inflammation induced by CPIs can also affect tissues adjacent to metastatic lesions. Based on the authors' clinical observation, with early beginning of CPI therapy, acute inflammation may occur without any other symptoms. In most cases, these adverse events remain self-limiting and easily manageable. General principles revolve around managing mild toxicity with observation only, and considering local steroids in cases of moderate toxicity. There is no need to add an antibiotic, unless bacterial/fungal infection is confirmed. For severe toxicity, systemic steroids may be required. Clinically, erythema occurs within metastatic melanoma lesions in the skin, as well as in the surrounding skin area (Figures $3 \mathrm{~A}, \mathrm{~B}$ ).

\section{Pruritus}

During treatment with ipilimumab, pruritus is usually associated with irritation, dryness and rash, and is an expression of increased activity of the immune system [28]. Persistent pruritus during therapy with anti-PD-1 and anti-PD-L1 inhibitors always requires dermatological consultation in order to exclude bullous pemphigoid in the so-called non-bullous form [29]. In contrast to the drug-induced variant of bullous pemphigoid, which usually disappears after discontinuation of treatment, the duration of the variant associated with the use of anti-PD-1 and anti-PD-L1 inhibitors may persist for up to several months after discontinuation of treatment [29].

\section{Other rare skin complications during therapy with anti-PD-1, anti-PD-L1 and anti-CTLA-4 inhibitors}

The following other rare skin complications may occur during combined anti-PD-1 and anti-CTLA-4 therapy: erythrodysaesthesia syndrome, i.e. the so-called handfoot syndrome, urticaria, toxic epidermis necrolysis and hypersensitivity reactions to UV radiation [30]. Stomatitis, alopecia, hyperhidrosis, and epidermal peeling have been reported in patients treated with nivolumab [13, 31]. Patients receiving pembrolizumab may also experience dry skin, change of hair colour, and alopecia [17, 32, 33].

\section{Management of skin toxicities during treatment with checkpoint inhibitors}

The treatment of skin complications that occur during therapy with immune checkpoint inhibitors depends on the severity of these symptoms. The severity is determined based on the Common Terminology Criteria for Adverse Events (CTCAE) (Table 2) [21]. The extent of skin lesions can be assessed by estimation of the total body 

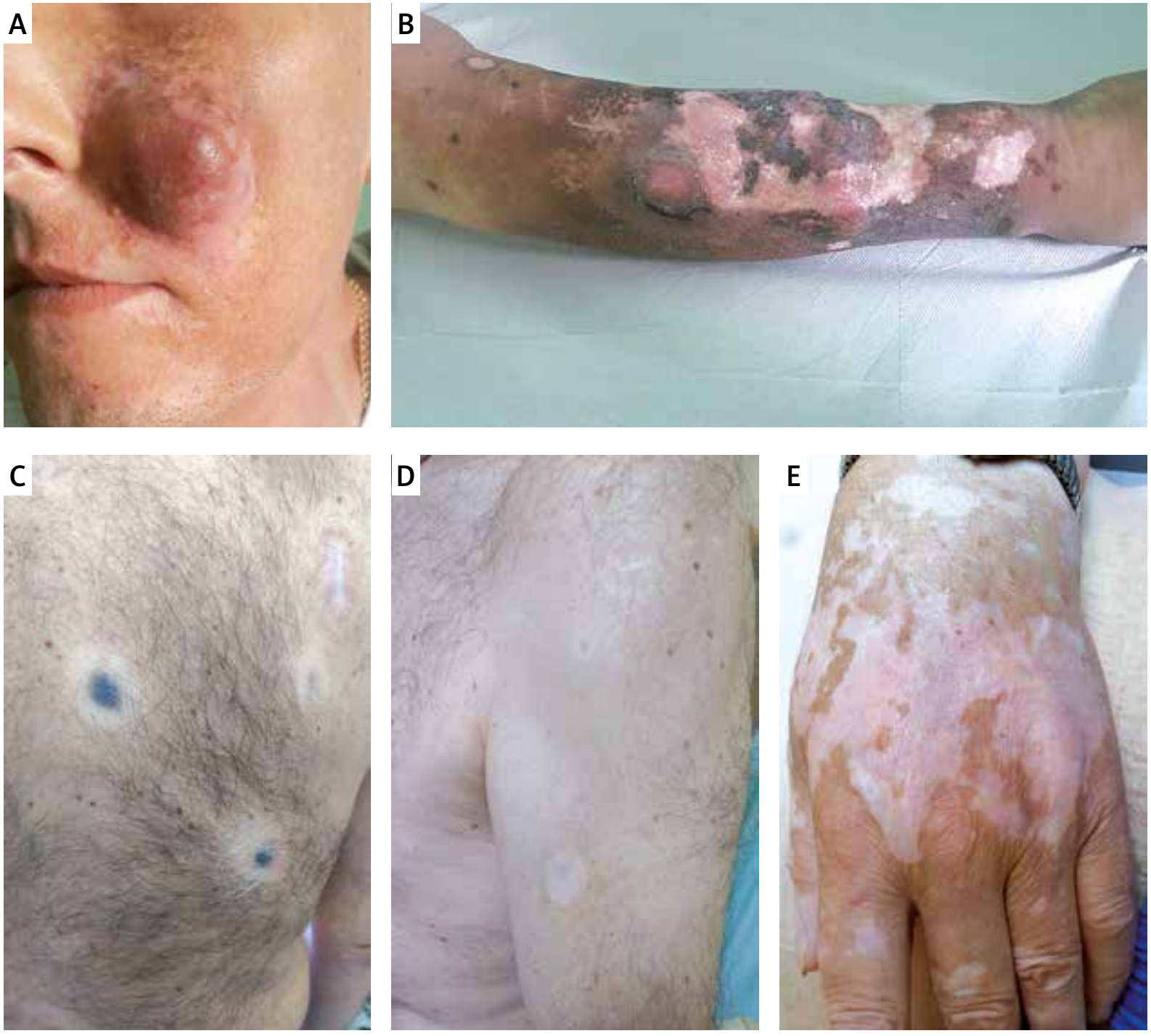

Figure 2. A - Vitiligo-like depigmentation after 6 months of anti-PD-1 therapy (CTCEA grade 1) within metastatic melanoma tumours on the face. B - Vitiligo-like depigmentation after 6 months of anti-PD-1 therapy (CTCEA grade 1) within the scar after excised primary melanoma lesion on the anterior surface of the left lower leg. $\mathbf{C}$ - Vitiligo-like depigmentation lesions within metastatic melanoma of the skin after a few months of anti-PD-1 treatment for metastatic melanoma. D - Vitiligo-like depigmentation lesions within selected melanocytic naevi after a few months of anti-PD-1 treatment for metastatic melanoma. E - Classical vitiligo-like depigmentation within the dorsal hands (CTCAE grade 1) that occurred after a few months of anti-PD-1 treatment for metastatic melanoma
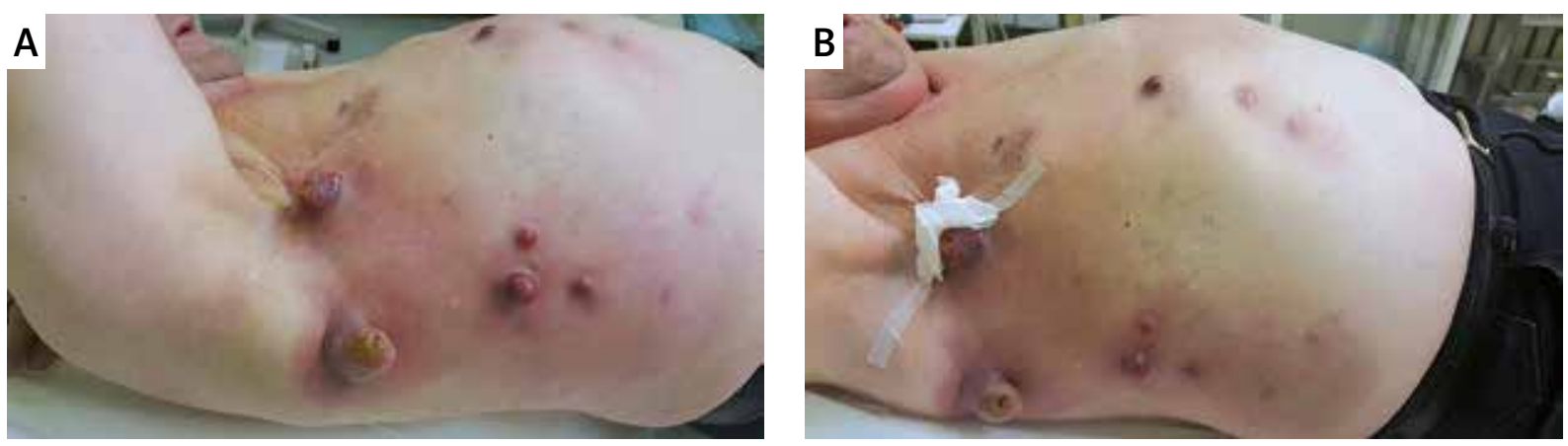

Figure 3. A - Acute inflammation (CTCEA grade 1) in the skin around metastatic lesions after the second dose of anti-PD-1 therapy. B - After 3 weeks the inflammation partially resolved without any therapy 
Table 2. The severity of skin irAEs based on the Common Terminology Criteria for Adverse Events (CTCAE) [21]

\begin{tabular}{ll}
\hline Grade & Description \\
\hline G1 & Skin lesions cover < $10 \%$ of the body surface area with or without symptoms (e.g. itching, burning, etc.) \\
\hline G2 & $\begin{array}{l}\text { Skin lesions cover 10-30\% of the body surface area with or without symptoms (e.g. itching, burning, etc.), limited daily } \\
\text { activities }\end{array}$ \\
\hline G3 & Skin lesions cover > 30\% of the body surface area or G2 with significant clinical symptoms, limited self-care \\
\hline G4 & $\begin{array}{l}\text { Epidermal detachment and necrosis, skin lesions cover }>30 \% \text { of the body surface area, accompanying symptoms } \\
\text { (erythema, purpura, epidermal detachment) }\end{array}$ \\
\hline
\end{tabular}

Table 3. Body surface area - classification based on the rule of nines to assess the surface of affected skin in skin toxicities (adapted from [28])

\begin{tabular}{lc}
\hline Body area & \% of total body surface area \\
\hline Head and neck & 9 \\
\hline Upper limb & 18 \\
\hline Front of the body (anterior surface of the chest and abdomen) & 18 \\
\hline Back of the body (back of the chest and lumbar region) & 18 \\
\hline Lower limbs & 1 \\
\hline Perineal area & 18 \\
\hline
\end{tabular}

surface area affected (<10\%, 10-30\%, > 30\%) using the Lund-Browder chart (so-called rule of nines), which so far has been used in the assessment of the extent of burns (Table 3) [28].

In case of grade 1 skin lesions, immunotherapy (antiPD-1/PD-L1, anti-CTLA-4) can be continued. However, the following actions should be taken: physical examination with comprehensive assessment of the patient's skin, advice on preventive measures to avoid skin irritation and exposure to UV radiation, regular application of emollients, and the use of high photoprotection. In addition, mild local glucocorticosteroids are recommended once daily, and in case of pruritus, oral or topical antihistamines may be considered; moreover, other dermatoses that may suggest skin toxicity (viral, bacterial, fungal infections or other drug-induced lesions) should be excluded.

In grade 2 skin lesions, the procedure is similar to those in grade 1 . However, if no improvement is achieved after one week of treatment, therapy with anti-PD-1/ PD-L1 or anti-CTLA-4 should be discontinued. Dermatological consultation and biopsy of the skin lesion for histopathological evaluation should be considered. In the case of grade 2 (or higher) skin irAEs with a clinical manifestation that is nonspecific and difficult to assess, especially with combined therapy (ipilimumab with nivolumab), dermatological consultation is necessary to exclude dermatological conditions that could be exacerbated as a result of treatment (psoriasis, toxic epidermis necrolysis, lichenoid dermatitis, bullous pemphigoid and scleroderma-like reactions).
If skin lesions do not improve or worsen despite the treatment, or grade 3 skin complications occur, immunological treatment (anti-PD-1/PD-L1, anti-CTLA-4) should always be stopped. The primary treatment in this case is systemic glucocorticosteroids. In mild to moderate lesions, oral prednisone should be used at a dose of 0.5$1 \mathrm{mg} / \mathrm{kg}$ bw/day (or equivalent). In case of severe lesions, intravenous glucocorticosteroids should be used: methylprednisolone $0.5-1 \mathrm{mg} / \mathrm{kg}$ bw 1-2 times a day (or another product at an equivalent dose). If the lesions improve, oral glucocorticosteroids should be used. In case of good response to glucocorticosteroids, a gradual dose reduction and withdrawal within 2-4 weeks is recommended. In patients with grade 3 skin manifestations, dermatological consultation and photographic documentation of the skin lesions are recommended. Excision biopsy of a skin lesion for histopathological evaluation can be considered. Restart of immunotherapy is only possible if the severity of skin lesions is reduced to grade 1 or 2 (mild). In any case, further treatment options, potential benefits of immunotherapy and the risk of further complications should be discussed with both the patient and the consulting dermatologist.

In case of grade 4 skin complications, immunological treatment (anti-PD-1/PD-L1, anti-CTLA-4) should be definitely discontinued. There is always a need for urgent dermatological consultation and the use of systemic glucocorticosteroids: (methyl)prednisolone 1-2 mg/ kg bw IV 1-2 times daily. Biopsy of a skin lesion should be taken for histopathological evaluation, and photographic documentation of the affected skin should be obtained. 
Proceed with immunotherapy

G1

Skin lesions cover $<10 \%$ of body surface area with or without symptoms (e.g. itching, burning, etc.)
G2

Skin lesions cover $10-30 \%$ of body surface area with or without symptoms (e.g. itching, burning, etc.), limited daily activities
Proceed with immunotherapy (anti-PD-1/PD-L1, anti-CTLA-4)

- Physical examination of the patient's entire skin

- Recommend preventive measures: avoiding skin irritation and exposure to UV radiation, regular use of emollients, and the use of effective photoprotection

- Use local mild glucocorticosteroids once daily

- In case of pruritus, consider oral or topical antihistamines

- Exclude other causes for skin lesions: viral, bacterial, fungal infections or other drug-induced rashes

No improvement or worsening

of symptoms
G3

Skin lesions cover $>30 \%$ of body surface area or grade 2 with significant clinical symptoms, limited self-care
G4

Epidermal detachment and necrosis, skin lesions cover $>30 \%$ of body surface area, accompanying symptoms (erythema, purpura, epidermal detachment)
Proceed with immunotherapy

Proceed with immunotherapy (anti-PD-1/PD-L1, anti-CTLA-4)

- Withhold immunotherapy if no improvement to G1 after 1 week

- Physical examination of the patient's entire skin

- Recommend preventive measures as in G1

- Use moderate to high strength topical glucocorticosteroids twice daily

- Consider oral or topical antihistamines

- Exclude other causes for skin lesions: viral, bacterial, fungal infections or other drug-induced rashes

- Consider dermatological consultation

- Consider biopsy of a skin lesion for histopathological assessment

No improvement or worsening of symptoms
Withhold immunotherapy (anti-PD-1/PD-L1, anti-CTLA-4)

- Physical examination of the patient's entire skin

- Recommend preventive measures as in G1

- Use high strength topical glucocorticosteroids twice daily

- Use oral antihistamines

- Use oral glucocorticosteroids: prednisone $0.5-1 \mathrm{mg} / \mathrm{kg}$ bw once daily for 3 consecutive days (gradually withdraw over 1-2 weeks) if the lesions are mild to moderate, or methylprednisone $0.5-1 \mathrm{mg} / \mathrm{kg}$ bw intravenously - if the lesions are severe (once therapeutic response is achieved, switch to oral glucocorticosteroids and gradually withdraw over 2-4 weeks)

- Dermatological consultation is advised

- Consider biopsy of a skin lesion for histopathological evaluation, and obtain photographic documentation of the affected skin

- Re-start immunotherapy only when the severity of skin lesions is reduced to grade 1 or 2 (mild), following discussion of further treatment options with the patient and the consulting dermatologist

Figure 4. An algorithm for prophylactic and therapeutic management of skin toxicities depending on the severity of skin irAEs according to the Common Terminology Criteria for Adverse Events (CTCAE) of the ESMO guidelines in the authors' modification $[19,39]$ 
Hospitalisation at a dermatology or burn department is advised in close cooperation with the dermatologist. In the case of a good response to glucocorticosteroid treatment, it can be switched to oral drugs with gradual dose reduction (within a few to several weeks, due to the possibility of recurrence of skin lesions in the case of too rapid withdrawal of glucocorticosteroids) [19, 22, 23, 28, 34-39]. The proposed algorithm for the prophylaxis and treatment of dermal toxicity is presented in Figure 4.

Whenever skin irAEs occur, diagnostic workup is advised for irAEs affecting other organs (e.g. the lungs, liver, gastrointestinal tract, endocrine system, etc.).

With long-term use of steroids, consideration should be given to prophylaxis of gastric ulcer disease (proton pump inhibitors), prophylaxis of osteoporosis (calcium, vitamin $D_{3}$ ), management of electrolyte disturbances (potassium level), and prophylaxis of Pneumocystis jirovecii infection.

\section{Conclusions}

In the aspect of dynamic development of new melanoma therapies, including the use of checkpoint inhibitors, the occurrence of selected skin toxicities significantly impairs the patient's quality of life, and in some cases it is necessary to immediately discontinue therapy or adjust the dose, which reduces the chances for improving the patient's overall survival.

In this aspect, knowledge of proper therapeutic management of selected skin toxicities is an essential element of knowledge in the work of every clinician - dermatologist, oncologist, and surgeon.

\section{Conflict of interest}

B. Cybulska-Stopa received honoraria for speaker, consultancy or advisory role from: MSD, BMS, Novartis, Roche, Pierre Fabre. Other authors declare no conflict of interest.

\section{References}

1. Krawczyk P, Wojas-Krawczyk K. Monoclonal antibodies against immune checkpoints in immunotherapy of cancer patients. Onkol Prak Klin 2015; 11: 76-86.

2. Alsaab HO, Sau S, Alzhrani R, et al. PD-1 and PD-L1 checkpoint signaling inhibition for cancer immunotherapy: mechanism, combinations, and clinical outcome. Front Pharmacol 2017; 8: 561.

3. Thallinger C, Füreder T, Preusser M, et al. Review of cancer treatment with immune checkpoint inhibitors: current concepts, expectations, limitations and pitfalls. Wien Klin Wochenschr 2018; 130: 85-91.

4. Ostrov DA, Shi W, Schwartz JC, et al. Structure of murine CTLA-4 and its role in modulating T cell responsiveness. Science 2000; 290: 816-9.

5. Swatler J, Kozłowska E. Immune checkpoint-targeted cancer immunotherapies. Postepy Hig Med Dosw 2016; 70: 25-42.
6. Gong J, Chehrazi-Raffle A, Reddi S, et al. Development of PD-1 and PD-L1 inhibitors as a form of cancer immunotherapy: a comprehensive review of registration trials and future considerations. J Immunother Cancer 2018; 6: 8.

7. Robert C, Thomas L, Bondarenko I, et al. Ipilimumab plus dacarbazine for previously untreated metastatic melanoma. N Engl I Med 2011; 364: 2517-26.

8. Maio M, Grob JJ, Aamdal S, et al. Five-year survival rates for treatment-naive patients with advanced melanoma who received ipilimumab plus dacarbazine in a phase III trial. Clin Oncol 2015; 33: 1191-6.

9. Hodi FS, O'Day SJ, McDermott DF, et al. Improved survival with ipilimumab in patients with metastatic melanoma. N Engl J Med 2010; 363: 711-23.

10. Ascierto PA, Del Vecchio M, Robert C, et al. Ipilimumab $10 \mathrm{mg} / \mathrm{kg}$ versus ipilimumab $3 \mathrm{mg} / \mathrm{kg}$ in patients with unresectable or metastatic melanoma: a randomised, doubleblind, multicentre, phase 3 trial. Lancet Oncol 2017; 18: 611-22.

11. McDermott DF, Drake CG, Sznol M, et al. Survival, durable response, and long-term safety in patients with previously treated advanced renal cell carcinoma receiving nivolumab. Clin Oncol 2015; 33: 2013-20.

12. Weber JS, D'Angelo SP, Minor D, et al. Nivolumab versus chemotherapy in patients with advanced melanoma who progressed after anti-CTLA-4 treatment (CheckMate 037): a randomised, controlled, open-label, phase 3 trial. Lancet Oncol 2015; 16: 375-84.

13. Robert C, Long GV, Brady B, et al. Nivolumab in previously untreated melanoma without BRAF mutation. Engl I Med 2015; 372: 320-30.

14. Hamid O, Puzanov I, Dummer R, et al. Final analysis of a randomised trial comparing pembrolizumab versus investigator-choice chemotherapy for ipilimumab-refractory advanced melanoma. Eur J Cancer 2017; 86: 37-45.

15. Larkin J, Chiarion-Sileni V, Gonzalez R, et al. Combined nivolumab and ipilimumab or monotherapy in untreated melanoma. N Engl J Med 2015; 373: 23-34.

16. Ugurel S, Röhmel J, Ascierto PA, et al. Survival of patients with advanced metastatic melanoma: the impact of novel therapies-update 2017. Eur J Cancer 2017; 83: 247-57.

17. Belum VR, Benhuri B, Postow MA, et al. Characterisation and management of dermatologic adverse events to agents targeting the PD-1 receptor. Eur J Cancer 2016; 60: 12-25.

18. Curry JL, Tetzlaff MT, Nagarajan P, et al. Diverse types of dermatologic toxicities from immune checkpoint blockade therapy. J Cutan Pathol 2017; 44: 158-76.

19. Haanen JBAG, Carbonnel F, Robert C, et al.; ESMO Guidelines Committee. Management of toxicities from immunotherapy: ESMO Clinical Practice Guidelines for diagnosis, treatment and follow-up. Ann Oncol 2017; 28 (Suppl 4): iv119-42.

20. Weber JS, Kähler KC, Hauschild A. Management of immunerelated adverse events and kinetics of response with ipilimumab. J Clin Oncol 2012; 30: 2691-7.

21. Common Terminology Criteria for Adverse Events (CTCAE) version 4.0 published: May 28, 2009 U.S. Department of Health and Human Services National Institutes of Health, National Cancer Institute.

22. Lacouture ME, Wolchok JD, Yosipovitch G, et al. Ipilimumab in patients with cancer and the management of dermatologic adverse events. J Am Acad Dermatol 2014; 71: 161-9.

23. de Golian E, Kwong BY, Swetter SM, et al. Cutaneous complications of targeted melanoma therapy. Curr Treat Options Oncol 2016; 17: 57. 
24. Hua C, Boussemart L, Mateus C, et al. Association of vitiligo with tumor response in patients with metastatic melanoma treated with pembrolizumab. JAMA Dermatol 2016; 152: 45-51.

25. Freeman-Keller M, Kim Y, Cronin H. Nivolumab in resected and unresectable metastatic melanoma: characteristics of immune-related adverse events and association with outcomes. Clin Cancer Res 2016; 22: 886-94.

26. Teulings HE, Limpens J, Jansen SN, et al. Vitiligo-like depigmentation in patients with stage III-IV melanoma receiving immunotherapy and its association with survival: a systematic review and meta-analysis. J Clin Oncol 2015; 33: 773-81.

27. Di Giacomo AM, Danielli R, Guidoboni M, et al. Therapeutic efficacy of ipilimumab, an anti-CTLA-4 monoclonal antibody, in patients with metastatic melanoma unresponsive to prior systemic treatments: clinical and immunological evidence from three patient cases. Cancer Immunol Immunother 2009; 58: 1297-306.

28. Fecher LA, Agarwala SS, Hodi FS, et al. Ipilimumab and its toxicities: a multidisciplinary approach. Oncologist 2013; 18: 733-43.

29. Naidoo J, Schindler K, Querfeld C, et al. Autoimmune bullous skin disorders with immune checkpoint inhibitors targeting PD-1 and PD-L1. Cancer Immunol Res 2016; 4: 383-9.

30. Hassel JC, Heinzerling L, Aberle J, et al. Combined immune checkpoint blockade (anti-PD-1/anti-CTLA-4): evaluation and management of adverse drug reactions. Cancer Treat Rev 2017; 57: 36-49.

31. Brahmer J, Reckamp KL, Baas P. Nivolumab versus docetaxel in advanced squamous-cell non-small-cell lung cancer. N Engl J Med 2015; 373: 123-35.

32. Robert C, Schachter J, Long GV, et al.; KEYNOTE-006 investigators. Pembrolizumab versus ipilimumab in advanced melanoma. N Engl J Med 2015; 372: 2521-32.

33. Eigentler TK, Hassel JC, Berking C, et al. Diagnosis, monitoring and management of immune-related adverse drug reactions of anti-PD-1 antibody therapy. Cancer Treat Rev 2016; 45: 7-18.

34. Kumar V, Chaudhary N, Garg M. Current diagnosis and management of immune related adverse events (irAEs) induced by immune checkpoint inhibitor therapy. Front Pharmacol 2017; 8: 49.

35. Lemech C, Arkenau HT. Novel treatments for metastatic Cutaneous melanoma and the management of emergent toxicities. Clin Med Insights Oncol 2012; 6: 53-66.

36. Linardou H, Gogas H. Toxicity management of immunotherapy for patients with metastatic melanoma. Ann Transl Med 2016; 4: 272.

37. Peuvrel L, Dréno B. Dermatological toxicity associated with targeted therapies in cancer: optimal management. Am J Clin Dermatol 2014; 15: 425-44.

38. Świtaj T, Wysocki P, Wojtukiewicz M, et al. Ipilimumab progress in therapy of advanced melanoma. Onkol Prakt Klin 2011; 7: 231-45.

39. Ziobro M, Cybulska-Stopa B, Kamińska-Winciorek G, et al. Bezpieczeństwo immunoterapii - zasady postępowania profilaktyczno-terapeutycznego w przypadku wystąpienia działań niepożądanych. Via Medica, Gdańsk 2018. 